\title{
СОВЕРШЕНСТВОВАНИЕ ТЕХНОЛОГИИ ПЕРЕРАБОТКИ ЗЕРНА ПШЕНИЦЫ НА РОТОРНО-ЛОПАСТНОМ ШЕЛУШИТЕЛЕ
}

D.V. Salykhov, V.N. Nevzorov, I.V. Matskevich

\section{THE IMPROVEMENT OF WHEAT GRAIN PROCESSING TECHNOLOGY ON ROTARY AND BLADED HUSKER}

Салыхов Дмитрий Викторович - асп. каф. технологии, оборудования бродильных и пищевых производств Красноярского государственного аграрного университета, г. Красноярск.

E-mail: salykhov.dmitry@gmail.com

Невзоров Виктор Николаевич - д-р с.-х. наук, проф., зав. каф. технологии, оборудования бродильных и пищевых производств Красноярского государственного аграрного университета, г. Красноярск. E-mail: nevzorov1945@mail.ru

Мацкевич Игорь Викторович - канд. техн. наук, ст. преп. каф. технологии, оборудования бродильных и пищевых производств Красноярского государственного аграрного университета, г. Красноярск. E-mail: imatskevichv@mail.ru

Цель исследования - совершенствование технологии шелушения зерна пшеницы на основе новой конструкции роторно-лопастного рабочего органа технологического оборудования. Представлены результаты исследования, выполненного с иелью совершенствования технологии переработки зерна пшеницы на разработанном роторно-лопастном шелушителе. Исследованы процессы шелушения зерна пшеницы по существующим технологиям, определены основные конструктивные недостатки серийно выпускаемого технологического оборудования, заключающиеся в том, что при шелушении зерна пшеницы на серийно выпускаемых шелушильных машинах с использованием абразивных рабочих органов происходит удаление до 20-25 \% от массы зерна. Для повышения эфффективности процессов шелушения была разработана новая технологическая схема, позволяющая производить поэтапное шелушение зерна с разделением продукции шелушения на фракции в виде плодовой и семенной оболочек, алейронового и субалей-
Salykhov Dmitry Victorovich - Post-Graduate Student, Chair of Technology, Equipment of Fermentative and Food Production, Krasnoyarsk State Agrarian University, Krasnoyarsk.

E-mail: salykhov.dmitry@gmail.com

Nevzorov Victor Nikolaevich - Dr. Agr. Sci., Prof., Head, Chair of Technology, Equipment of Fermentative and Food Productions, Krasnoyarsk State Agrarian University, Krasnoyarsk.

E-mail: nevzorov1945@mail.ru

Matskevich Igor Victorovich - Cand. Techn. Sci., Senior Lecturer, Chair of Technology, Equipment of Fermentative and Food Production, Krasnoyarsk State Agrarian University, Krasnoyarsk.

E-mail: imatskevichv@mail.ru

ронового слоев, зародыша и эндосперм. Сфоормированы основные требования к новой конструкции машины для шелушения зерна пшеницы, которые заключаются в создании нового рабочего органа, позволяющего производить обработку зерна по ресурсосберегающей технологии. По результатам проведенных патентных исследований по российской и зарубежной информационным базам разработана новая конструкция технологического оборудования, предназначенного для поэтапного шелушения зерна пшеницы с использованием роторно-лопастного рабочего органа, авторские права на новую конструкцию шелушителя защищены патентом Российской Федерации № 2709719 «Машина для шелушения зерна», на базе которого разработана нормативнотехническая документация и изготовлена опытная лабораторная установка. Представлены результаты испытания опытной лабораторной установки в сравнении с серийно выпускаемой шелушильной машиной «Восход ЗШM-1,5». 
Ключевые слова: зерно пшеницы, совершенствование технологии, патентные исследования, кинематическая схема, роторнолопастное шелушение.

The research objective was the improvement of technology of wheat grain processing on the basis of a new design of rotary and blade working body of processing equipment. The results of the research performed for the purpose of the improvement of the technology of processing of wheat grain on developed rotary and bladed husker were presented. The processes of flaking wheat grain using existing technologies were investigated, the main constructive shortcomings of serially let out processing equipment which were at wheat grain flaking by serially released flaking cars to use abrasive working bodies up to $20-25 \%$ of the grain mass were removed. A new technological scheme allowing making a stage-by-stage of grain flaking with division of flaking production into fractions in the form of fruit and seed shells, aleyron and subaleyron, germ and endosperm was developed for increasing the efficiency the processes of flaking. The main requirements to a new machine design for flaking wheat grain consisting in creation of a new working body allowing making processing of the grain on resource-saving technology were formulated. By the results of conducted patent researches on Russian and foreign information bases a new design of processing equipment intended for a stage-bystage peeling of grain of wheat with using rotary and bladed working body was developed, the copyright of a new design of the husker was protected by the patent of the Russian Federation No. 2709719 "The machine for grain peeling" on the basis of which the specifications and technical documentation were developed and experimental laboratory installation was made. The results of the test of experimental laboratory installation in comparison with serially released flaking car Voskhod ZSHM-1.5 were presented

Keywords: wheat grain, improvement of technology, patent researches, kinematic scheme, rotor-blade peeling.

Введение. Наиболее перспективной отраслью сельского хозяйства для Российской Федерации является зерноперерабатывающая промышленность, так как зерно является основным сырьем для многих отраслей пищевой и перерабатываю- щей промышленности. В Сибирском федеральном округе валовой сбор зерна пшеницы составил 9849,8 тыс. т, лидерами являются Алтайский край - 2967,2 тыс. т, Новосибирская область 1712,1 тыс. т и Красноярский край с объемом сбора зерна пшеницы 1461,7 тыс. т, что по сравнению с 2018 г. в 2019 г. выше на $12 \%[5,6]$.

Основным направлением переработки зерна пшеницы является мукомольная отрасль, где производятся продукты питания С повышенными потребительскими свойствами: мука, крупы, хлеб и хлебобулочные изделия, макаронные и кондитерские изделия. Основной технологической операцией, влияющей на качество муки и готовой продукции в целом, является шелушение. Выполненные исследования процессов шелушения на серийном оборудовании с использованием абразивного рабочего органа приводят к тому, что в отходы уходит до 20$25 \%$ от массы шелушенного зерна. Разработанная технологическая операция роторнолопастного шелушения направлена на поэтапную очистку зерна от плодовой и семенной оболочки, алейронового и субалейронового слоев, а также отделение зародыша и эндосперма.

Выполненные научно-исследовательские работы [2-4] направлены на совершенствование технологии и оборудования для фермерских хозяйств.

Цель исследования: совершенствование технологии шелушения зерна пшеницы на основе новой конструкции роторно-лопастного рабочего органа технологического оборудования.

\section{Задачи исследования:}

1) изучить технологию шелушения зерна пшеницы и разработать технологическую схему раздельного оголения зерна пшеницы по биологическим признакам строения зерна;

2) провести патентные исследования для выбора аналога и прототипа, используемых при разработке технического решения шелушильной машины с роторно-лопастным рабочим органом;

3) изготовить опытно-лабораторную установку по полученному патенту на изобретение и провести экспериментальные исследования по шелушению зерна пшеницы.

Объекты и методы исследования. Объектами исследования для производства высококачественной хлебопекарной муки является зерно пшеницы и разработка технологии поэтапного 
шелушения зерна пшеницы с разделением продуктов шелушения на фракции с использованием разработанной новой конструкции технологического оборудования.

Методами исследования является проведение патентных исследований согласно ГОСТ Р 15.011-96 «Патентные исследования. Система разработки и постановки продукции на производство» по российской и зарубежной информационным базам, выбор аналога и прототипа для разработки новой конструкции машины для шелушения зерна пшеницы.

Обработка экспериментальных данных проводилась статистическими методами.
Результаты исследования и их обсуждение. Анализ существующих технологий шелушения зерна пшеницы показал, что при абразивном воздействии на поверхность зерна вместе с семенными и плодовыми оболочками удаляется алейроновый и субалейроновый слои, а также зародыш, что приводит к образованию отходов в виде отрубей $[3,4]$. Для устранения установленного недостатка разработана новая технология шелушения зерна пшеницы с раздельным сбором алейронового и субалейронового слоев и зародыша. Разработанная технологическая схема поэтапного шелушения зерна пшеницы приведена на рисунке 1.

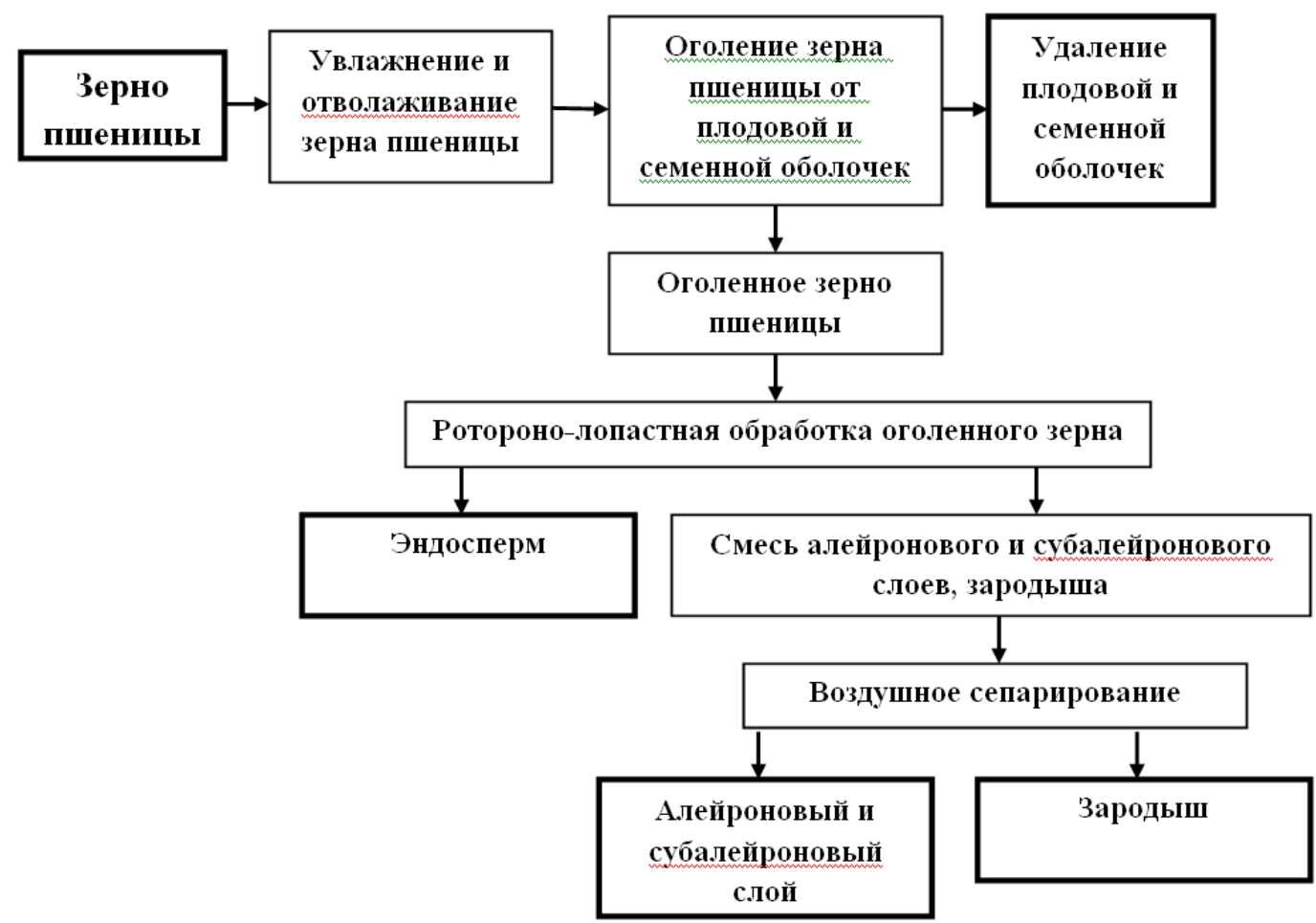

Puс. 1. Технологическая схема шелушения зерна пшеницы

Для реализации технологического процесса роторно-лопастного шелушения зерна пшеницы по разработанной технологической схеме (см. рис. 1) были проведены патентные исследования и выявлен аналог (патент РФ № 2302899 «Вихревой шелушитель зерновых материалов») и прототип (патент РФ № 2491124 «Шелушильносушильная машина»). По результатам анализа выявленных патентов разработана конструкция нового устройства для шелушения зерна пшеницы, в которой для обеспечения наилучшего качества продуктов шелушения используется более тонкая детальная обработка каждого зерна, при этом на первом этапе снимается только оболочка зерна, на втором этапе происходит отделение эндосперма и выделение из смеси зародыша, алейронового и субалейронового слоя. Авторские права на разработанную конструкцию защищены патентом Российской Федерации № 2709719 «Машина для шелушения зерна», кинематическая схема конструкции приведена на рисунке $2[1,4]$. 

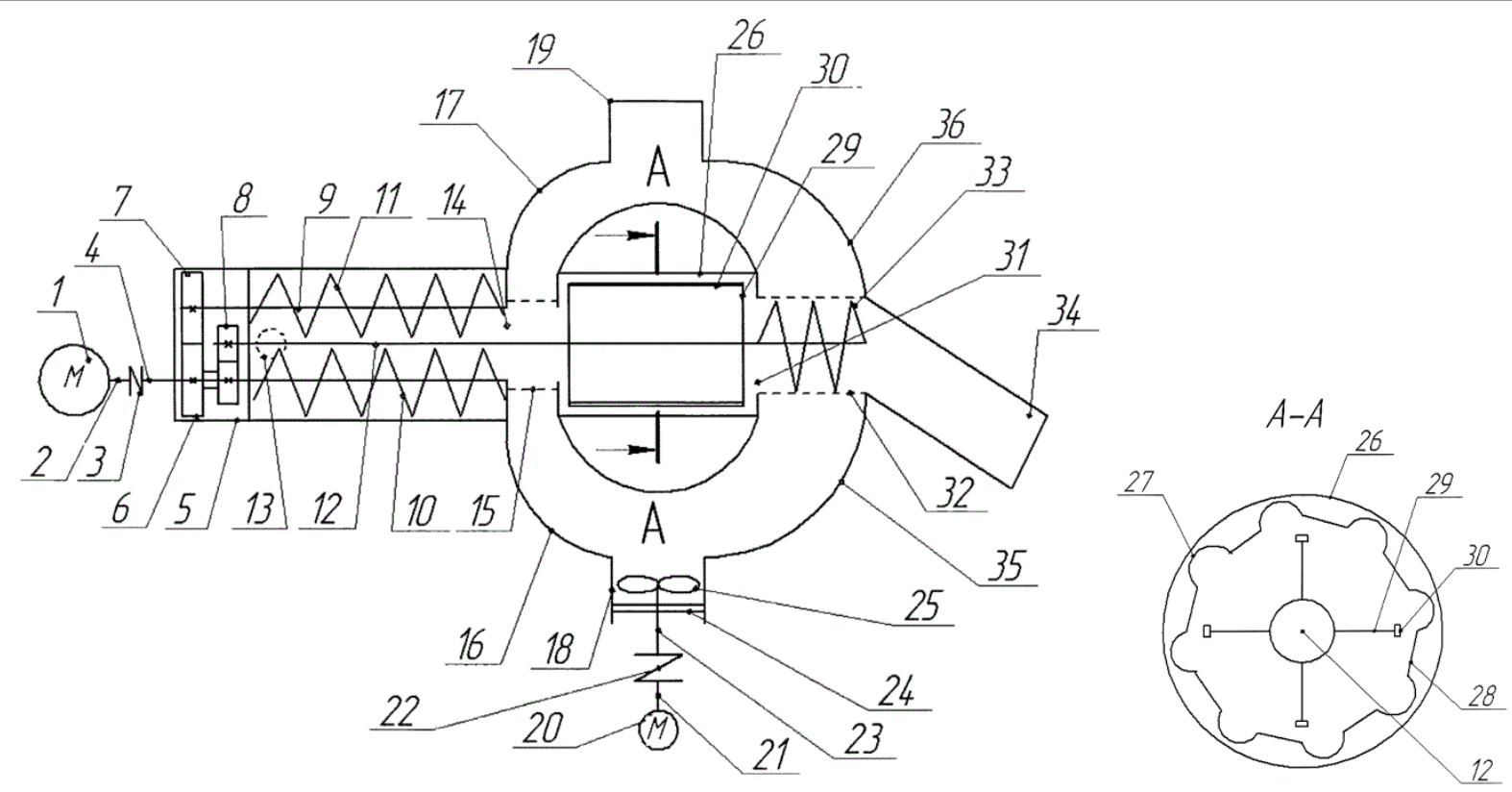

Puc. 2. Кинематическая схема машины для шелушения зерна

Машина для шелушения зерна работает следующим образом. Включаются электродвигатели 1 и 20, при этом электродвигатель 1 через вал 2 муффту 3 передает крутящий момент на приводной вал 4, установленный в корпусе 5. В загрузочное отверстие 13 подается зерно для шелушения. При вращении приводного вала 4, на котором установлен шнек 10, вращается жестко установленная двойная зубчатая шестерня 6, которая в свою очередь одновременно передает крутящий момент через зубчатую шестерню 7 валу 9 с установленным шнеком 11 и зубчатую шестерню 8 рабочему валу 12. При попадании зерна на шнеки 10 и 11, которые имеют противоположную навивку и вращаются навстречу друг другу, зерно, взаимодействуя между собой, обеспечивает предварительную очистку и перемещается к выходному отверстию 14. Из выходного отверстия 14 зерно попадает в сетчатый барабан первичной очистки 15 , где происходит очищение зерна потоком воздуха путем удаления шелухи и сора через отводящий воздуховод 17 к выходной трубе 19. Поток воздуха образуется за счет работы электродвигателя 20, передающего крутящий момент через установленную на выходном валу 21 мусту 22 приводному валу 23, на котором в свою очередь установлен вентилятор 25. При вращении вентилятора 25 происходит забор воздуха из нагнетательной трубы 18 через фильтр 24, при этом нагнетаемый воздух распределяется по подводящим воздуховодам 16 и 35. Далее зерно, прошедшее первичную обработку, поступает в шелушильный барабан 26, где взаимодействует с вращающимися шелушильными лопастями 29, установленными на рабочем валу 12, и отбрасывается к внутренней поверхности шелушильного барабана 26, имеющего на одинаковом расстоянии друг от друга 28 проточки 27. При попадании зерна на внутреннюю поверхность шелушильного барабана 26 зерно контактирует с обрезиненным наконечником 30 шелушильной лопасти 29, установленной на рабочем валу 12 , и продвигается по внутренней поверхности шелушильного барабана 27 с периодическим ослаблением давления в проточках 28 к выходному отверстию 31. Далее шелушенное зерно и частицы наружной оболочки поступают через выходное отверстие 31 шелушильного барабана 26 в неподвижно закрепленный сетчатый барабан окончательной очистки 32 , соединенного с подводящим воздуховодом 35 и отводящим воздуховодом 36. В сетчатом барабане окончательной очистки 32 установленный на рабочем валу 12 транспортирующий шнек 33 перемещает смесь шелушенного зерна и частицы оболочки к отверстию выгрузки 34, при этом под воздействием потока воздуха из нагнетательной трубы 18 частицы шелушенной наружной оболочки отделяются и через отводящий воздухо- 
вод 36 удаляются через выходную трубу 19, а при оформлении заявки на изобретение позвошелушенное очищенное зерно выходит через отверстие выгрузки 34.

Результаты патентных исследований и разработка нормативно-технической документации

лили разработать конструкторскую документацию и изготовить опытный образец машины для шелушения зерна (рис. 3).

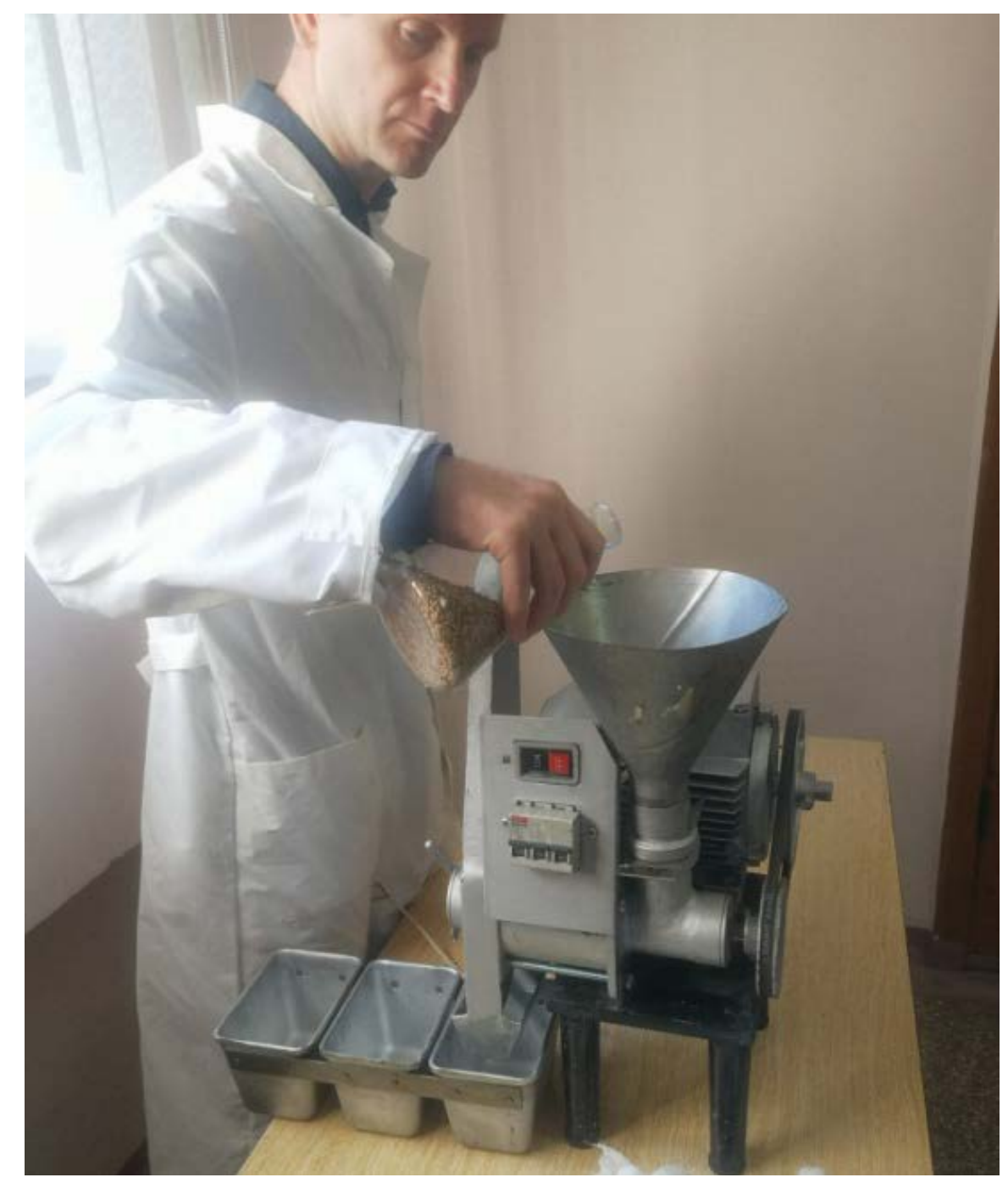

Рис. 3. Общий вид машины для шелушения зерна пшеницы

Экспериментальные работы по шелушению зерна пшеницы проводились на кафедре «Технология, оборудование бродильных и пищевых производств» Института пищевых производств Красноярского ГАУ с использованием метода активного планирования экспериментов для обоснования оптимальных конструктивных параметров новой конструкции машины для шелушения зерна пшеницы.
Оценка качества шелушения проводилась путем разделения шелушенного зерна на фракции (рис. 4).

По результатам выполненных экспериментальных исследований был выполнен сравнительный анализ качественных показателей шелушенного зерна на машине шелушильной «Восход 3ШМ-1,5» и опытной экспериментальной установке «Машина для шелушения зерна», изготовленной по патенту РФ № 2709719 , который приведен в таблице 1. 


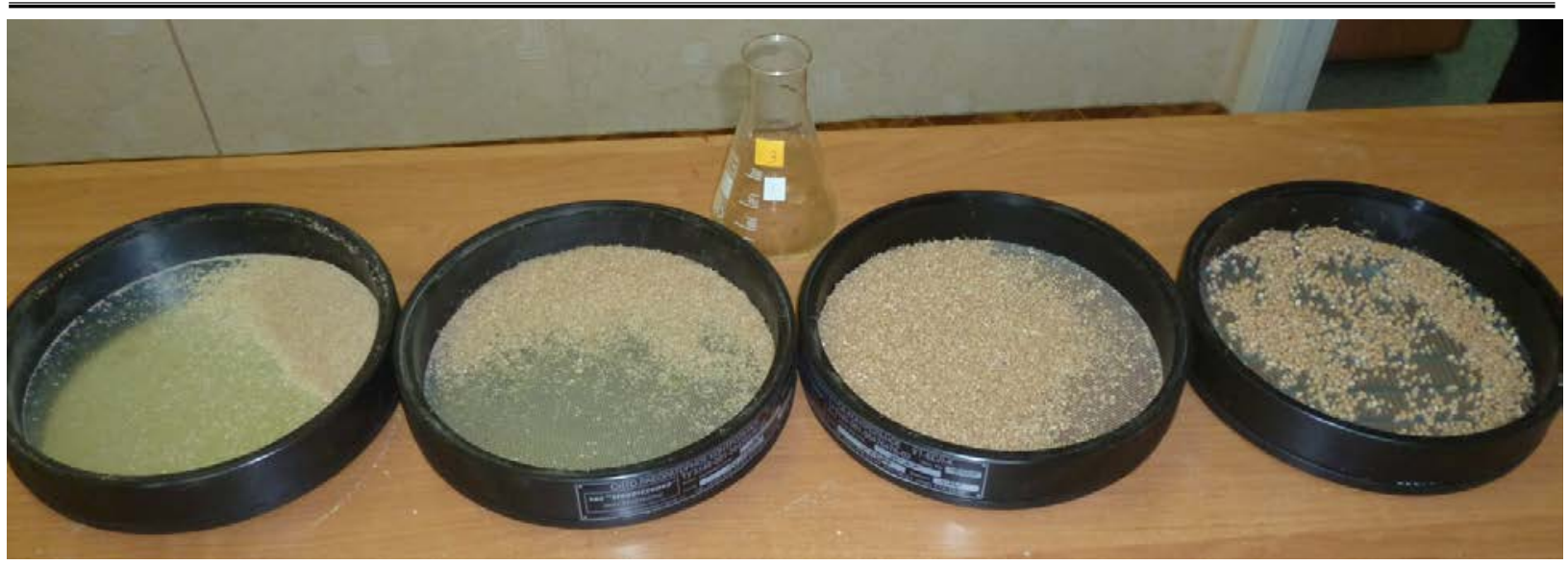

Pис. 4. Фракции шелушенного зерна

Таблица 1

Сравнительный анализ результатов шелушения зерна пшеницы

\begin{tabular}{|l|c|c|}
\hline \multirow{2}{*}{\multicolumn{1}{|c|}{ Продукт }} & \multicolumn{2}{c|}{ Выход продукта, \% } \\
\cline { 2 - 3 } & $\begin{array}{c}\text { «Восход } \\
\text { 3ШМ-1,5» }\end{array}$ & $\begin{array}{c}\text { Опытная роторно-лопастная машина } \\
\text { для шелушения зерна }\end{array}$ \\
\hline Шелушенное зерно & 93,1 & 98,1 \\
\hline Мучка & 3,2 & 1,3 \\
\hline Битые зерна & 3,7 & 0,6 \\
\hline
\end{tabular}

Анализ результатов испытания шелушильных машин, приведенный в таблице 1, показал, что выход цельного шелушенного зерна по новой разработанной технологии увеличился на $10,5 \%$, выход мучки уменьшился на 4,6 \%, выход битых зерен уменьшился на 1,6\%.

\section{Выводы}

1. В зерноперерабатывающей промышленности основной технологической операцией при производстве высококачественной муки для выпечки хлебобулочных и кондитерских изделий является шелушение зерна пшеницы, при котором необходимо решить проблему снижения количества отходов в виде отрубей и увеличение качества муки за счет использования алейронового и субалейронового слоев зерна пшеницы.

2. Выполненные патентные исследования по Российской и мировой базам данных позволили определить аналог и прототип изобретений используемых при разработке нового оборудования, основанного на принципе роторнолопастного шелушения зерна пшеницы, новизна конструкции которого защищена патентом РФ № 2709719 «Машина для шелушения зерна».
3. На основе полученного патента РФ № 2709719 «Машина для шелушения зерна» разработана конструкторская документация и изготовлена опытно-лабораторная машина для шелушения зерна пшеницы с роторнолопастным рабочим органом. Результаты экспериментальных исследований показали, что по сравнению с машиной «Восход ЗШМ-1,5» опытная шелушильная машина обеспечивает выход цельного шелушенного зерна выше на 10,5 \%.

\section{Литература}

1. Пат. 2709719 RU, МПК В02B 5/02. Машина для шелушения зерна / Невзоров В.Н., Мацкевич И.В., Тепляшин В.Н., Кавкин Р.В., Сальххо Д.В.; заявитель и патентообладатель ФГБОУ ВО «Красноярский государственный аграрный университет». № 2018 130591; заявл. 22.08.2018; опубл. 19.12. 2019.

2. Невзоров В.Н., Кожухарь Е.Н., Сальхов Д.В. и др. Оптимизация технологического процесса шелушения зерна пшеницы // Известия вузов. Пищевая технология. 2018. № 1. C. 78-83. 
3. Невзоров В.Н., Мацкевич И.В., Сальххо Д.В. и др. Технология и оборудование для шелушения зерна пшеницы // Вестник КрасГАУ. 2018. № 6. C. 162-166.

4. Невзоров В.Н., Хижняк С.В., Янова М.А. и др. Технология и оборудование биотехнологической переработки зерна злаковых культур / Краснояр. гос. аграр. ун-т. Красноярск, 2019. 148 с.

5. Российский сельскохозяйственный центр: заключительная информация о качестве зерна нового урожая. URL: https://rosselhos center.com.

6. Koptseva N.P., Kirko V.I., Nevzorov V.N. et al. Development of the Russian economy's agricultural sector in 2015-2016 // SGEM International Multidisciplinary Scientific Conference on Social sciences and Arts. 2017. № 1-4. C. 221-228.

\section{Literatura}

1. Pat. 2709719 RU, MPK V02V 5/02. Mashina dlja shelushenija zerna / Nevzorov V.N., Mackevich I.V., Tepljashin V.N., Kavkin R.V., Salyhov D.V.; zajavitel' i patentoobladatel'
FGBOU VO «Krasnojarskij gosudarstvennyj agrarnyj universitet». № 2018130591; zajavl. 22.08.2018; opubl. 19.12.2019.

2. Nevzorov V.N., Kozhuhar' E.N., Salyhov D.V. i dr. Optimizacija tehnologicheskogo processa shelushenija zerna pshenicy // Izvestija vuzov. Pishhevaja tehnologija. 2018. № 1. S. 78-83.

3. Nevzorov V.N., Mackevich I.V., Salyhov D.V. i dr. Tehnologija i oborudovanie dlja shelushenija zerna pshenicy // Vestnik KrasGAU. 2018. № 6. S. 162-166.

4. Nevzorov V.N., Hizhnjak S.V., Janova M.A. i dr. Tehnologija i oborudovanie biotehnologicheskoj pererabotki zerna zlakovyh kul'tur I Krasnojar. gos. agrar. un-t. Krasnojarsk, 2019. $148 \mathrm{~s}$.

5. Rossijskij sel'skohozjajstvennyj centr: zakljuchitel'naja informacija o kachestve zerna novogo urozhaja. URL: https://rosselhoscenter.com.

6. Koptseva N.P., Kirko V.I., Nevzorov V.N. et al. Development of the Russian economy's agricultural sector in 2015-2016 // SGEM International Multidisciplinary Scientific Conference on Social sciences and Arts. 2017. № 1-4. S. 221-228. 